\title{
Squamous Cell Malignancies of the Upper Urinary Tract: A Survival Study and a Systematic Review of the Literature
}

Anthony Pham ${ }^{1}$, Gerald Colvin ${ }^{1}$ and David Berz ${ }^{1,2 *}$

${ }^{1}$ Brown University, Providence, RI

${ }^{2}$ The City of Hope, Comprehensive National Cancer Center, Duarte, CA

\begin{abstract}
Background: Carcinomas of the renal pelvis and ureter are rare diseases. Previous reports suggest that squamous cell histology is associated with inferior survival. We present one of the largest population based analysis to date of survival in patients with upper urinary tract malignancies and a systematic review of the subject.

Methods: We analyzed the Surveillance, Epidemiology and End Results database for cancer specific survival rates in patients with renal pelvis and ureteral malignancies who were diagnosed between 1973 and 2004 in the SEER catchment geographic areas. The primary exposure of interest was the underlying histology, squamous cell versus transitional cell differentiation. We performed descriptive statistics, non parametric survival analysis, and cox proportional hazard analysis.
\end{abstract}

Results: We identified 13,213 eligible patients, 7,716 renal pelvis and 5,497 ureteral carcinomas. Among this cohort, 179 patients had squamous cell carcinoma (SCC), 12,395 had transitional cell carcinoma (TCC), including 121 papillary, and 619 had other histologies. Overall, patients with SCC histology fared worse. The median overall survival time was 10 months for SCC and 63 months for TCC. The cox analysis revealed a HR 3.7 (95\% Cl 3.0-4.5) for SCC when compared to TCC and corrected for decade of diagnosis, age, gender, prior treatment, and race. The difference between the two groups was entirely attributable to survival differences in patients with loco-regional disease. However, when stratified by lymph node involvement this difference disappeared for patients with locally involved lymph nodes $(p=0.84)$ and for patients with clear lymph nodes $(p=0.92)$.

Conclusions: SCCs of the upper urinary tract present at a higher clinical stage and appear to represent more aggressive disease when compared to other histologies. However, when appropriately staged according to lymph node status, the survival of TCC and SCC of the upper urinary tract is identical when compared stage by stage.

\section{Introduction}

Neoplasms of the upper urogenital tracts involving the renal pelvis and ureter are defined as any neoplastic growth involving the lining of the urinary tract from the renal calyces to the ureterovesical junction [1]. These tumors are rare representing less than one percent of genitourinary malignancies $[2,3]$. The incidence of neoplasms of the upper urinary tract in the United States has increased slightly over the last 20 years from an annual incidence of 0.69 to $0.73 / 1000,000$ person years from 1973 to 1996 [4]. The paucity of cases makes it difficult to establish a standard of care for these malignancies and the prognosis remains poor. Squamous cell histology represents only a small fraction of the total number of malignancies of the upper urinary tract (UUT). Most of our knowledge about these rare malignancies originates from anecdotal evidence and squamous cell histology, has been associated with a poor prognosis in early reports [5-10]. Several studies have challenged this assumption. We present one of the largest registry studies and systematic literature reviews of UUT malignancies to date and investigate the impact of squamous cell histology on overall and cancer specific survival.

\section{Methods}

\section{Review of the literature}

We reviewed the publicly available medical and science databases (i.e. Pubmed, Chemical Abstracts Service, Directory of Open Access Journals, EBSCO Academic Search Complete, Google Scholar, Index Copernicus, Intute, OAlster, Open J-Gate, Pubget, Pubmed Central, SCOPUS, Socolar) for relevant publications. Where indicated direct correspondence with the author was initiated. We utilized the following search terms: ${ }^{*}$ upper urinary tract, ${ }^{*}$ malignancies, ${ }^{*}$ squamous cell carcinoma, ${ }^{*}$ transitional cell carcinoma, ${ }^{*}$ urothelial carcinoma, ${ }^{*}$ ureter, ${ }^{*}$ renal pelvis, ${ }^{*}$ calyces, ${ }^{*}$ survival, ${ }^{*}$ outcome and ${ }^{*}$ treatment. All articles were reviewed by the authors and evaluated for established quality characteristics [11]. Articles were included in our evaluation, if they compared the incidence, prevalence or outcome of squamous cell carcinomas of the upper urinary tract with other histologies in the same anatomical location.

\section{The database}

For our cohort we utilized publicly available data from the National Cancer Institute Surveillance, Epidemiology, and End Results (SEER) database from 1973 to 2004 . To allow for sufficient maturation, only patients presenting until the end of 2003 were included in the survival analysis. The SEER program is an effort by the United States (US) government to collect data and report cancer incidence, treatment, and survival. The database represents about 10 percent of the US population by collecting information from 14 population based cancer registries

*Corresponding authors: David Berz, MD, PhD, MPH, Brown University, Providence, RI, The City of Hope, Comprehensive National Cancer Center, Duarte, CA, USA, E-mail: berz@sbcglobal.net

Received August 09, 2011; Accepted November 25, 2011; Published November 27, 2011

Citation: Pham A, Colvin G, Berz D (2011) Squamous Cell Malignancies of the Upper Urinary Tract: A Survival Study and a Systematic Review of the Literature. J Cancer Sci Ther S4:001. doi:10.4172/1948-5956.S4-001

Copyright: (C) 2011 Pham A, et al. This is an open-access article distributed unde the terms of the Creative Commons Attribution License, which permits unrestricted use, distribution, and reproduction in any medium, provided the original author and source are credited. 
around the country. Trained abstractors collect data on patient age, sex, site, histological findings, tumor grade, and stage from hospital records, outpatient clinics, radiation centers, private laboratories and physician offices. For coding purposes the ICD-O-3 classification was used [12].

\section{Patients}

Patients were eligible if they presented between 1973 and 2004 with a malignancy of the renal pelvis or ureter (site coding C65.9 and C66.9). Only patients with a clearly malignant coded phenotype were included. The primary exposure of interest was the underlying histology. Histologies were subdivided into squamous cell (SC), transitional cell (TC), (including the papillary subtype) and other histologies (OT) (mainly small cell, sarcomatoid and undifferentiated carcinomas). The primary outcome of interest was cancer specific survival. We also examined overall survival and performed sensitivity analyses, excluding and right censoring patients who died from causes other than UUT malignancies. Since survival prognosticators in UUT malignancies are poorly delineated, we examined race, prior surgery and radiotherapy, decade of diagnosis, age at diagnosis, gender, preceding malignancies and stage as potential predictors of the primary outcome and cancer specific survival. Race was coded as Caucasian, Black, Hispanic or Asian/other. The other category included mainly smaller Asian subpopulations and the indigenous population of the Western hemisphere. Decade of diagnosis was coded into the $70 \mathrm{~s}$, 80 s, 90 s and 2000s, while the age group was subdivided into 49 or younger, 50 to 75 , and older than 75 years of age at diagnosis. Prior therapies were classified as having been received or not. Secondary to coding issues, we utilized the traditional American Joint Committee on Cancer (AJCC) staging classification, which entails the following stages: in situ, local, regional and distant. The regional stage included patients with extension beyond the ureter or renal pelvis and patients with documented lymph node involvement.

\section{Statistical methods}

We examined descriptive statistics to describe demographic composition of the study population and distribution of the other relevant predictors of the outcome. Univariate Kaplan Meier survival analysis was performed to investigate which variables were of predictive relevance. In our cancer specific survival analysis, the patients who died from a cause other than a malignancy of the upper urinary tract were right censored. Differences along the strata of predictors of interest were evaluated using a log rank test. If the log rank test was statistically significant, the covariates were retained in the final model. In the final model, we performed Cox proportional hazards regression to determine hazard ratios [13]. Post-estimation diagnostics were performed to analyze if the proportional hazard assumptions were violated, using graphical and computational methods [14]. All analyses were performed using STATA 9.0 (College Station, TX).

\section{Results}

\section{Systematic literature review}

We identified 41 studies that met the pre-specified criteria for further review. Only five of them provided information to compare the features of squamous cell carcinoma of the upper urinary tract (SCC-UUT) with other histologies in the same location. One of them compared the outcome of SCC-UUT with other rare histologies [5] and one did not provide sufficient information to compare survival as an outcome measure [15]. The remaining three studies included two single institution retrospective reviews and one high quality registry study comparing the survival of SCC-UUT and transitional cell carcinomas of the upper urinary tract (TCC-UUT) [16-18].

The reported results were mixed. The study from Virginia reported a disease specific mortality rate for patients with SCC-UUT of $77 \%$ versus only $46 \% 17$ for patients with TCC-UUT. The study from Scandinavia reported even less encouraging results for patients with SCC-UUT. The five year overall survival and 1 year post nephrectomy death rate for patients with SCC-UUT were $7 \%$ and $67 \%$, respectively, against $56 \%$ and $22 \%$ for TCC-UUT [18]. In contrast, a large scale, high quality registry study from Sweden which included 743 patients with transitional cell and 65 with squamous cell histology, revealed comparable outcome results for patients with SCC-UUT and TCCUUT, when equal stages were compared. The particular strength of this study was a central pathology review process of the majority of the specimens and the availability of clinical details from review of hospital records [16]. Table 1 depicts the patient characteristics and outcome results of selected studies, included into our review.

\section{Patients}

We identified 13,213 patients with malignancies of the UUT in our registry study. One hundred and ninety nine patients had squamous cell malignancies of the UUT and 12,395 had transitional or papillary histology. Baseline characteristics by histology are displayed in Table 1. Transitional carcinomas and other histologies demonstrated a male gender predominance, while the gender distribution for squamous cell carcinomas was equally balanced. Appropriate lymph node sampling in surgically resected cases was consistently reported in less than twenty percent, an observation that has persisted into the 21 st century. Patients with squamous cell malignancies were more likely to present with regional $(\mathrm{p}<0.01)$ and distant $(\mathrm{p}<0.01)$ disease, while TCC had a higher likelihood to present at a local $(\mathrm{p}<0.01)$ or in situ stage $(\mathrm{p}<0.01)$. Patients with squamous cell histology were less likely to undergo radiation therapy $(\mathrm{p}<0.01)$ and surgery $(\mathrm{p}<0.01)$ (Table 2$)$.

\section{Survival}

At the time of our analysis approximately $56 \%$ of patients with squamous cell malignancies of the upper urothelial tract had died from their underlying malignancies. The death rate from bladder tumors was consistently less than or equal to $1 \%$ (2 in the squamous cell group and 93 in the TCC group). The overall survival for patients who presented with UUT squamous cell cancer was significantly worse than for TCC (see Kaplan Meier graph A in graph 1). We examined race, prior surgery and radiotherapy, decade of diagnosis, age at diagnosis, gender, preceding malignancies and stage as other potential predictors of outcome and retained them in our final Cox proportional hazard (Cox $\mathrm{PH})$ model if they had a significant impact on survival on univariate, non parametric analysis. We retained race, prior surgery and/or radiotherapy, decade of diagnosis, age at diagnosis, gender and stage in our final model. Of note is that the covariate stage was introduced as described above, utilizing the above described staging classification, which collapses extension beyond the organ (renal pelvis or ureter) and local lymph node involvement into regional disease. We performed Cox proportional hazard modeling for cancer specific survival, adjusting for race, prior surgery and radiotherapy, decade of diagnosis, age at diagnosis, gender, preceding malignancies and stage. We then examined the survival difference for regional and metastatic disease across the three different histologies. As graphically illustrated in Kaplan Meier graph C, no significant difference in survival was established for patients presenting with metastatic disease. The major difference in survival is most notable in the patient group presenting with regional stage disease (graph B). 


\begin{tabular}{|c|c|c|c|c|c|c|c|}
\hline ڤ & 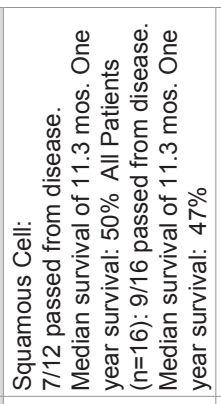 & 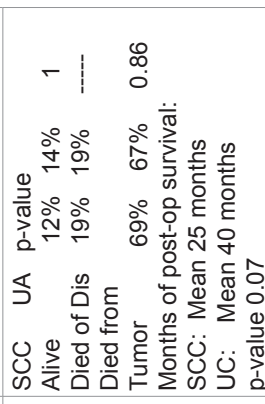 & 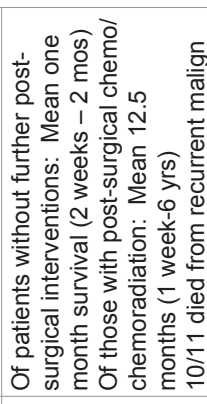 & 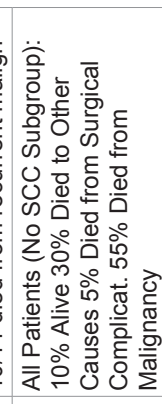 & 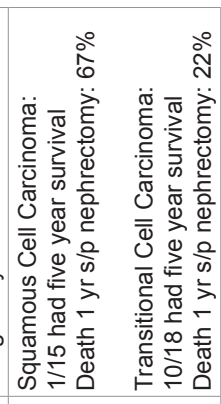 & 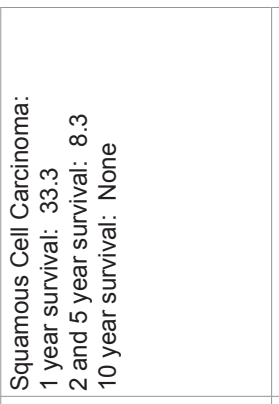 & 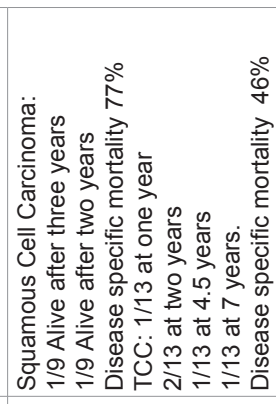 \\
\hline 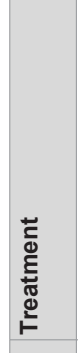 & 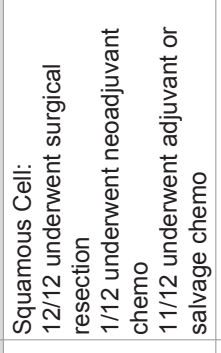 & 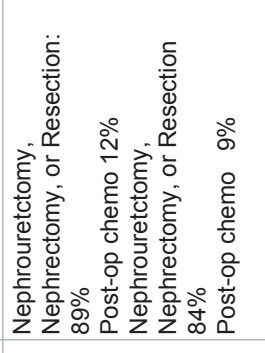 & 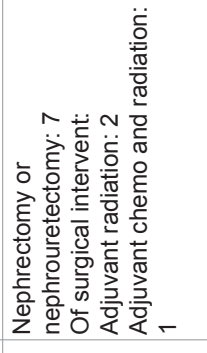 & 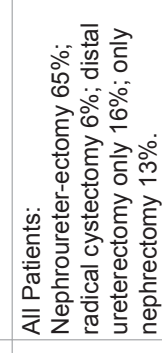 & 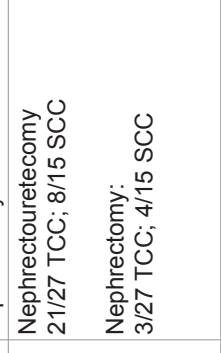 & 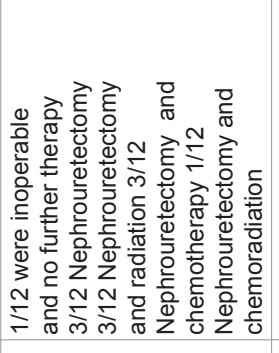 & 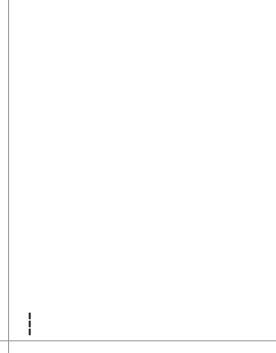 \\
\hline 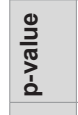 & 1 & 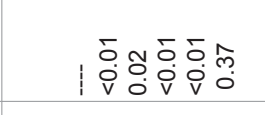 & 1 & a & 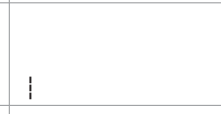 & 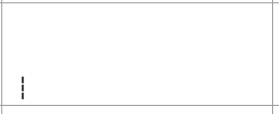 & 1 \\
\hline $\begin{array}{l}\text {. } \\
\text { क्ञ } \\
\text { के }\end{array}$ & 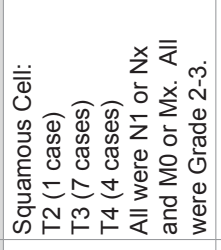 & 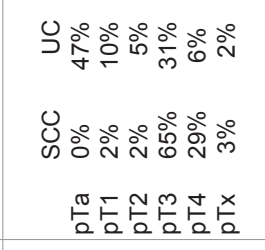 & 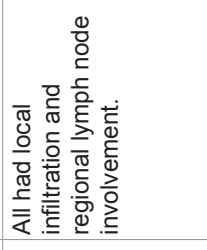 & 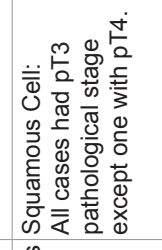 & 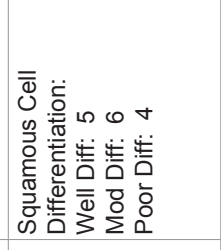 & 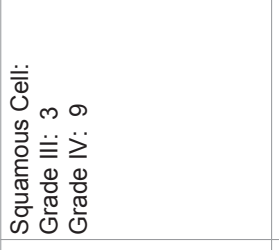 & 1 \\
\hline 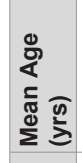 & 1 & 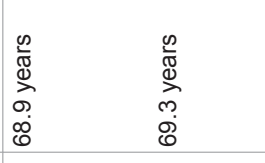 & 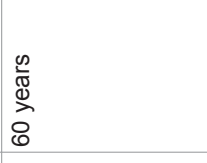 & 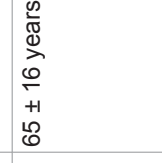 & 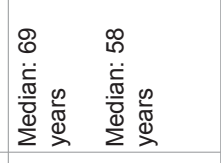 & 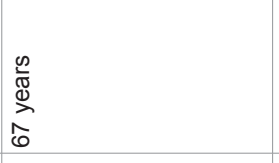 & 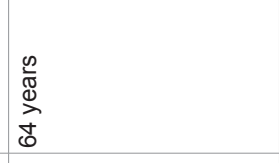 \\
\hline$\frac{0}{0}$ & $\cong$ & 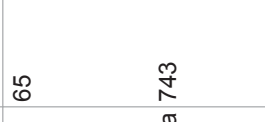 & $F$ & 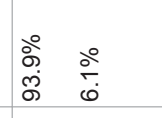 & $\stackrel{\circ}{\circ}$ & $\cong$ & \\
\hline & 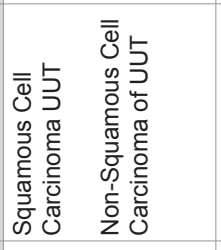 & 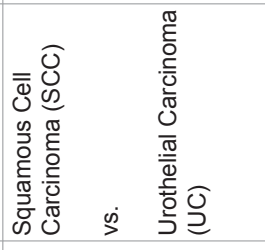 & 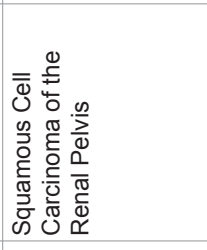 & 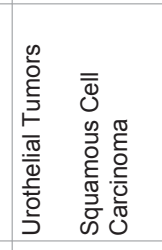 & 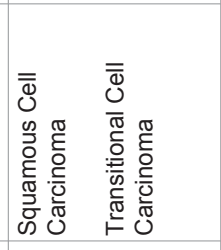 & 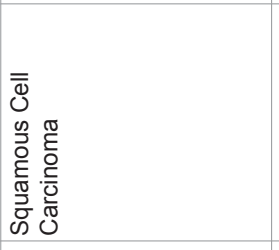 & 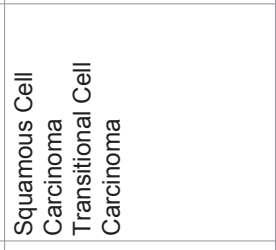 \\
\hline 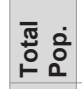 & $\stackrel{\varphi}{\circ}$ & 吕 & $\underset{7}{f}$ & m & $\mathscr{\vartheta}$ & 点 & N \\
\hline & 离 & 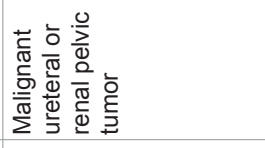 & 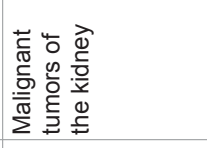 & 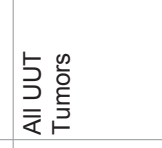 & 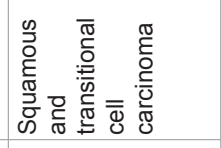 & 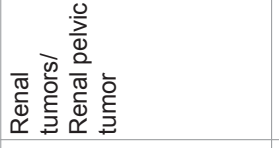 & 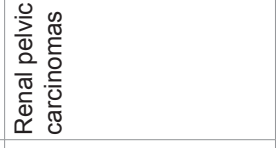 \\
\hline 要 & & 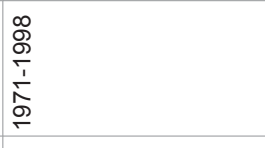 & 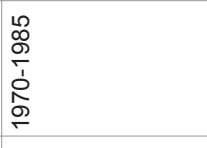 & 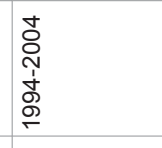 & 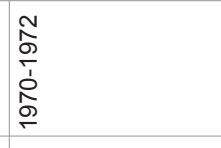 & 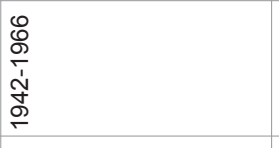 & 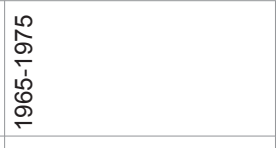 \\
\hline 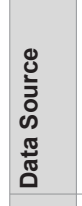 & 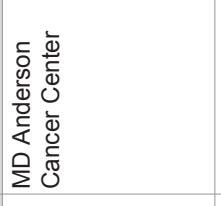 & 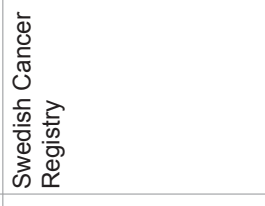 & 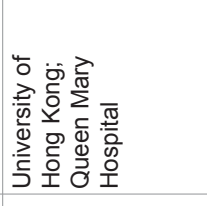 & 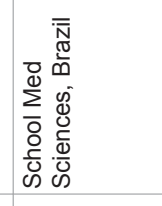 & 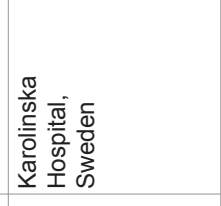 & 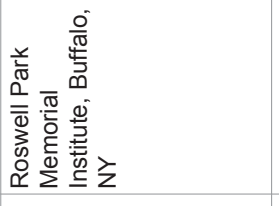 & 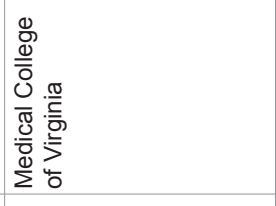 \\
\hline 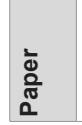 & 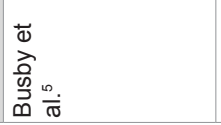 & 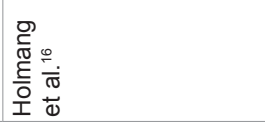 & 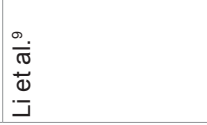 & 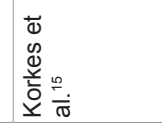 & 童 & 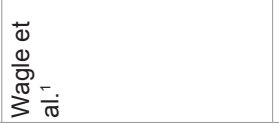 & 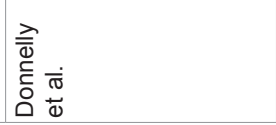 \\
\hline
\end{tabular}




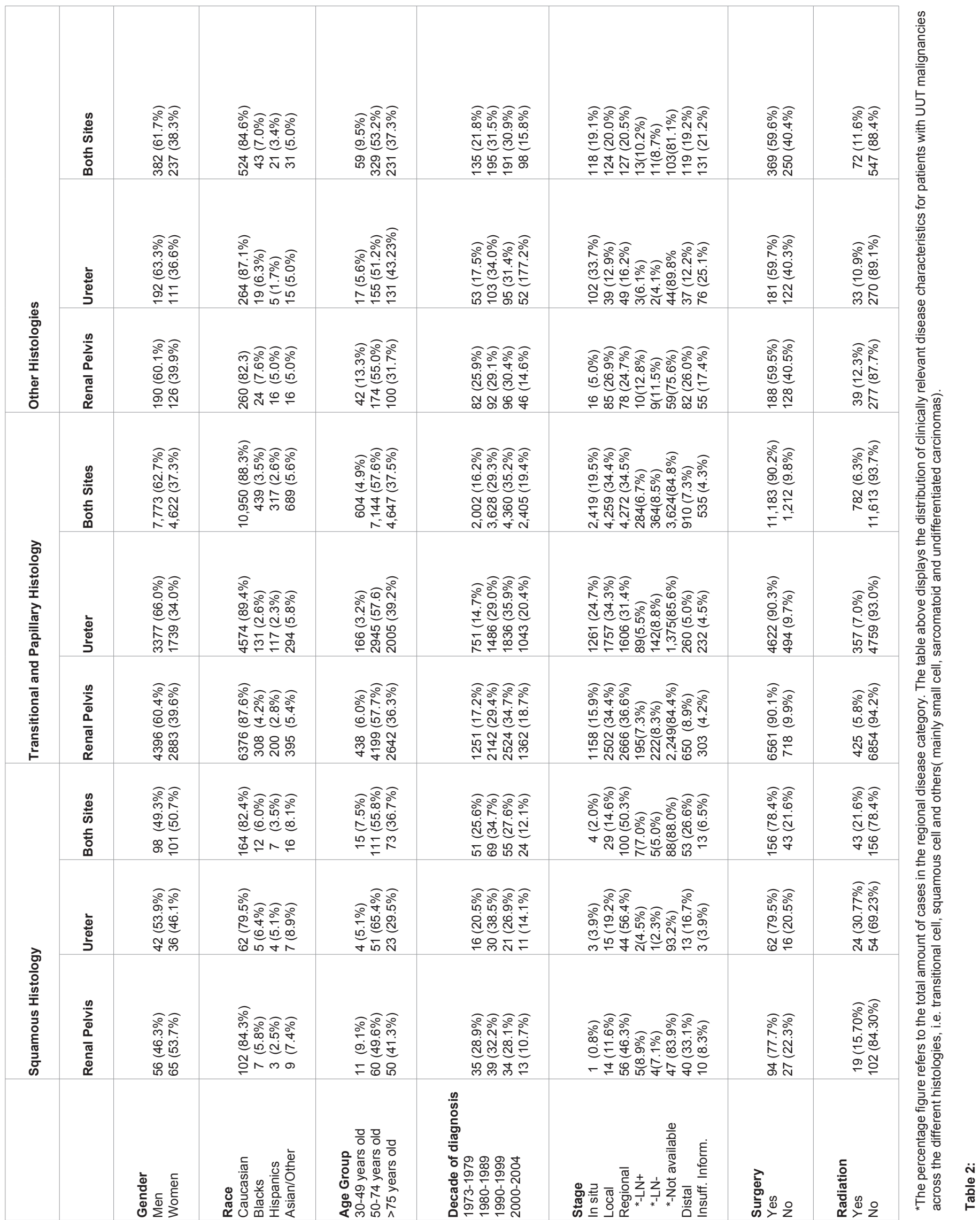




\begin{tabular}{|c|c|c|c|c|}
\hline Sites & HR Transitional Cell+ & HR Squamous Cell+ & HR Papillary+ & HR Other Histologies+ \\
\hline Renal Pelvis & $1^{*}$ & $4.30(95 \% \mathrm{Cl} 3.40-5.44)$ & $0.81(95 \% \mathrm{Cl} 0.47-1.39)$ & $1.28(95 \% \mathrm{Cl} 1.04-1.58)$ \\
\hline Ureter & $1^{*}$ & $3.05(95 \% \mathrm{Cl} 2.11-4.42)$ & $0.63(95 \% \mathrm{Cl} 0.24-1.69)$ & 0.99(95\% Cl 0.74-1.32) \\
\hline Both sites & $1^{*}$ & $3.68(95 \% \mathrm{Cl} 3.02-4.50)$ & $0.77(95 \% \mathrm{Cl} 0.48-1.25)$ & 1.10(95\% Cl 0.93-1.30) \\
\hline $\begin{array}{l}\text { Cancer speci } \\
\text { Six months } \\
\text { One year } \\
\text { Two years } \\
\text { Five years }\end{array}$ & $\begin{array}{l}94.0 \%(95 \% \mathrm{Cl} 59.8-73.9 \%) \\
89.7 \%(95 \% \mathrm{Cl} 89.2-90.3 \%) \\
84.5 \%(95 \% \mathrm{Cl} 83.8-85.2 \%) \\
79.1 \%(95 \% \mathrm{Cl} 78.2-79.9 \%)\end{array}$ & $\begin{array}{l}67.4 \%(95 \% \mathrm{Cl} 59.8-73.9 \%) \\
54.3 \%(95 \% \mathrm{Cl} 46.4-61.6 \%) \\
40.6 \%(95 \% \mathrm{Cl} 32.7-38.3 \%) \\
32.5 \%(95 \% \mathrm{Cl} 24.6-40.6 \%)\end{array}$ & $\begin{array}{l}97.2 \%(95 \% \text { Cl } 91.8-99.1 \%) \\
93.5 \%(95 \% \text { Cl } 86.9-96.9 \%) \\
90.4 \%(95 \% \text { Cl } 82.9-94.7 \%) \\
84.1 \%(95 \% \text { Cl } 74.8-90.2 \%)\end{array}$ & $\begin{array}{l}85.6 \%(95 \% \text { Cl } 82.3-88.3 \%) \\
80.0 \%(95 \% \text { Cl } 76.3-83.3 \%) \\
74.5 \%(95 \% \text { Cl } 70.3-78.1 \%) \\
68.2 \%(95 \% \text { Cl } 63.5-72.4 \%)\end{array}$ \\
\hline $\begin{array}{l}\text { Cancer speci } \\
\text { Six months } \\
\text { One year } \\
\text { Two years } \\
\text { Five years }\end{array}$ & $\begin{array}{l}67.4 \%(95 \% \mathrm{Cl} 64.4-70.2 \%) \\
51.9 \%(95 \% \mathrm{Cl} 48.6-55.1 \%) \\
36.9 \%(95 \% \mathrm{Cl} 33.4-40.4 \%) \\
25.9 \%(95 \% \mathrm{Cl} 22.2-29.7 \%)\end{array}$ & $\begin{array}{l}40.1 \%(95 \% \text { Cl } 25.8-54.0 \%) \\
30.3 \%(95 \% \text { Cl } 16.7-45.0 \%) \\
26.5 \%(95 \% \text { Cl } 13.4-41.5 \%) \\
18.9 \%(95 \% \text { Cl } 7.7-34.0 \%)\end{array}$ & $\begin{array}{l}\text { NA } \\
\text { NA } \\
\text { NA } \\
\text { NA }\end{array}$ & $\begin{array}{l}58.3 \%(95 \% \text { Cl } 47.9-67.4 \%) \\
45.6 \%(95 \% \text { Cl } 35.0-55.6 \%) \\
31.8 \%(95 \% \text { Cl } 20.9-43.3 \%) \\
20.0 \%(95 \% \text { Cl } 8.8-34.5 \%)\end{array}$ \\
\hline
\end{tabular}

*Reference group; +HR for cancer specific mortality, adjusted for race, prior surgery and radiotherapy, decade of diagnosis, age at diagnosis, gender and stage. The table above describes the survival of patients with UUT malignancies across different histologies. The upper part demonstrates the outcome of the Cox Proportional Hazard model, adjusted for race, prior surgery and radiotherapy, decade of diagnosis, age at diagnosis, gender and stage. Patients with transitional cell histology were considered the reference group. The second part shows the cancer specifc survival for all stages and for patients with stage IV only, respectively. The cancer specific survival for patients with stage IV disease and papillary histology could, secondary to a paucity of cases not be calculated.

Table 3:

As outlined in table 1 of the 4,499 patients with regional disease only 1,316 patients obtained appropriate lymph node sampling ( 26 with squamous, 2,232 with transitional cell and 58 with other histological subtype). In the group of patients with regional TCC, survival was significantly decreased in patients with positive lymph nodes $(\mathrm{p}<0.01)$ (graph D). In the small group of patients with SCC only a trend but no statistically significant survival difference could be observed in the patients with positive or absent lymph node involvement $(\mathrm{p}=0.63)$ (graph E) (Table 3) (Figure 1).

\section{Discussion}

Malignancies of the upper urinary tract are rare malignancies. The carcinomas of the renal pelvis has first been described by Rayer in 1841 and Hedenius published in 1878 the first specific case of squamous cell carcinoma of the upper urinary tract(UUT) [1]. Grace recommended almost half a century ago a radical uteronephrectomy with a thorough sampling of the loco-regional lymph nodes as most appropriate treatment for carcinomas for UUT [19].

One of our previous analyses suggested a relevance of the locoregional lymph node status for the outcome of patients with carcinomas of the UUT [20]. Hence, we present the largest registry based study of squamous cell malignancies of the upper urothelial tract to date and contextualize the results with findings in the literature with a specific focus on the data on loco-regional lymph node status.

Most previously published reports regarding the outcome of patients with SCC of the UUT are case reports or small series $[5-8,10]$. Two retrospective single institution studies compared the outcome of patients with SCC-UUT and TCC-UUT. Unfortunately none of these studies provided detailed information about the loco-regional extent and lymph node involvement $[17,18]$. The largest study published to date is a retrospective registry study from Sweden [16]. This Swedish study included 743 patients with transitional cell and 65 with squamous cell histology included a central review process of the majority of the resected specimens and reviewed clinical details from hospital records [16].

Our study reveals several interesting findings. First, SCC of the UUT present on average with more advanced stages when compared to TCCs. This can probably be explained by a more aggressive biology and a lower incidence of clinical warning signs, such as hematuria, in patients with SCC. Second, the overall survival for patients diagnosed in the US with SCC of the UUT is dismal and overall inferior to patients with TCC. Third, stage for stage the survival difference between squamous and transitional histologies is less pronounced. This is in accordance to the prior Swedish study by Holmang et al. [16], which demonstrated an equally poor prognosis for both tumor types when only advanced stages were considered. Holmang et al. [16] observed a trend towards a decreased survival in patients with pT3 with SCC that did not reach statistical significance $(p=0.099)$. In our study the survival difference at six and twelve months after diagnosis did reach statistical significance. This is largely due to the greater number of observed events thus resulting in a higher statistical power in our study. Fourth, our study demonstrates that patients with TCC involving the regional lymph nodes fare significantly worse than patients with disease extending beyond the organ. Interestingly, this survival difference is less pronounced in patients with SCC and regional disease. Unfortunately, the paucity of data on patients in our registry with SCC and regional disease of the UUT and the large fraction of patients with inadequate lymph node sampling does not allow for a firm conclusion regarding the prognostic relevance of local lymph node status in patients with SCC of the UUT.

Our study has several shortcomings. First, the SEER registry obtains information from medical charts and, therefore, the registry data can only be as accurate as the medical record from which it is obtained. Second, clinical history and comorbidities cannot be obtained from the SEER registry. This might have introduced a bias of differential attrition across the different histological subtypes into our study. In addition, the SEER registry provides insufficient information about the extent of post-operative therapy. Several studies have suggested some benefit from adjuvant chemotherapy [21-27] and no information about this modality is available in the SEER registry. Although information about post-operative radiotherapy is provided, this modality has never demonstrated a benefit to patient survival in UUT malignancies $[22,28]$ Lastly, the stage coding on patients with UUT malignancies was largely done in the old AJCC Staging system. This classification collapses local lymph node involvement and tumors exceeding the confinement of the involved organ into the regional stage category. As demonstrated above this leads to inaccurate prognostication, at least in TCCs. Hence, our reported hazard ratio has to be considered with caution. Despite these shortcomings, the size of this study and the quality of the performed 
Citation: Pham A, Colvin G, Berz D (2011) Squamous Cell Malignancies of the Upper Urinary Tract: A Survival Study and a Systematic Review of the Literature. J Cancer Sci Ther S4:001. doi:10.4172/1948-5956.S4-001
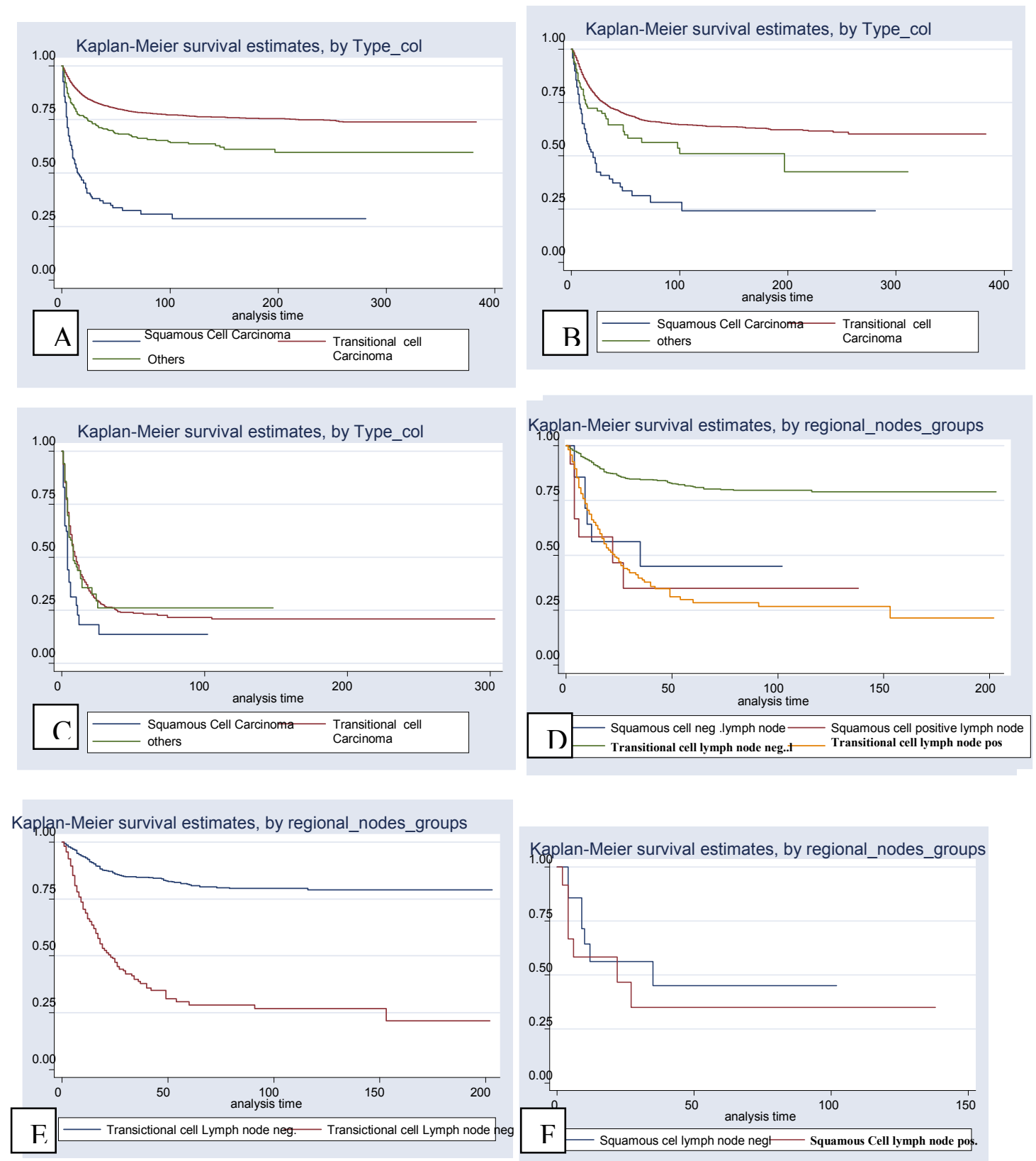

Figure 1: The panel above graphically illustrates the survival of patients with UUT malignancies. Graph A demonstrates the survival by histology. All stages are considered. Graph B considers only the patients presenting with regional disease, i.e. patients with malignancies beyond the confinement of the renal pelvis or ureter or positive lymph node involvement. Graph C displays the survival of patients with metastatic disease, by histology. Graph D illustrates the survival of patients with locoregional disease and known lymph node status. All histologies are included. Graph E demonstrates the superior survival of patients with absent lymph node involvement in patients with transitional cell histology and regional disease status. Graph F demonstrates the absence of a significant difference by lymph node status in patients with regional disease status and squamous cell histology.

statistical analysis does provide a valuable addition to the existing body of literature on squamous cell malignancies of the UUT.

Early outcome reports of patients with UTT carcinomas reported a wide spectrum of 5 year overall survival fractions. Whilst a survival of $82 \%$ of all patients with low grade lesions was reported [29], only $0-19 \%$ of all patients were alive after five years, if locoregional lymph node metastasis was detected on initial examination [30-32]. Patients with carcinomas of the UUT and loco-regional lymph node involvement have a prognosis comparable to metastatic disease. This is reflected in the current TNM staging classification [33], which considers regional lymph node involvement as stage IV disease. Regardless, inadequate lymph node sampling has been described in many of the more recent therapeutic studies on upper urinary tract malignancies [21-27]. In a single armed phase II Hellenic Cooperative Oncology Group study, investigating the adjuvant use of carboplatin and paclitaxel in patients with advanced carcinoma of the upper urinary tract, only $61 \%$ of all patients had a known status of the loco-regional lymph nodes [21]. 
In retrospective Canadian and Mayo clinic reports about the use of adjuvant systemic chemotherapy in high-risk UTT patients, only $80 \%$ and $61 \%$ of all patients had a known status of the loco-regional lymph nodes $[25,26]$. The shortcoming of unknown lymph node status in many of the recent studies on this disease entity complicates their interpretability.

\section{Conclusion}

Squamous cell cancers of the upper urinary tract are associated with a poor prognosis. Overall, patients with SCC present with more advanced disease and have lower survival rates when compared to their transitional cell counterparts. Lymph node dissection has not been a standard part of the surgical management of UUT. However, the lymph node status in patients with UUT provides further information to help give patients more accurate prognoses and potentially to guide further therapy. To improve this prognosis the rigorous future study of effective systemic chemotherapy for palliative and adjuvant treatment, especially in patients with advanced disease, is needed.

\section{References}

1. Wagle DC, Moore RH, Murphy GP (1974) Squamous cell carcinoma of the renal pelvis. J Urol 111: 453-455.

2. Williams CB, Mitchell JP (1973) Carcinoma of the ureter--a review of 54 cases. Br J Urol 45: 377-387.

3. Williams CB, Mitchell JP (1973) Carcinoma of the renal pelvis: a review of 43 cases. $\mathrm{Br} J$ Urol 45: 370-376.

4. Munoz, JJ Ellison LM (2000) Upper tract urothelial neoplasms: incidence and survival during the last 2 decades. J Urol 164: 1523-1525

5. Busby JE, Brown GA, Tamboli P, Kamat AM, Dinney CP, et al. (2006) Upper urinary tract tumors with nontransitional histology: a single-center experience. Urology 67: 518-523.

6. Diaz González R, Barrientos A, Larrodera L, Ruilope LM, Leiva O, et al. (1985) Squamous cell carcinoma of the renal pelvis associated with hypercalcemia and the presence of parathyroid hormone-like substances in the tumor. $J$ Urol 133: $1029-1030$

7. Kazarians B, Kausch I, Doehn C, Jocham D (2008) Squamous cell carcinoma of the renal pelvis. Therapeutic options for a rare entity]. Aktuelle Urol 39: 456458.

8. Kikuchi E, Horiguchi Y, Nakashima J, Hatakeyama N, Matsumoto M, et al (2005) Lymphovascular invasion independently predicts increased disease specific survival in patients with transitional cell carcinoma of the upper urinary tract. J Urol 174: 2120-2123.

9. Li MK, Cheung WL (1987) Squamous cell carcinoma of the renal pelvis. J Uro 138: 269-271.

10. Washino S, Terauchi F, Matsuzaki A, Kobayashi Y (2008) Two cases of squamous cell carcinoma of upper urinary tract with hypercalcemia. Nihon Hinyokika Gakkai Zasshi 99: 703-708.

11. Ressing M, Blettner M, Klug SJ (2009) Systematic literature reviews and metaanalyses: part 6 of a series on evaluation of scientific publications. Dtsch Arztebl Int 106: 456-463.

12. 12. International Classification of Diseases for Oncology, 3rd edn (ICD-O-3) (WHO: Geneva, ).

13. Parzen M, Lipsitz SR (1999) A global goodness-of-fit statistic for Cox regression models. Biometrics 55: 580-584.

14. Wei WH, Su JS (1999) Model choice and influential cases for survival studies. Biometrics 55: 1295-1299.

15. Korkes F, Silveira TS, Castro MG, Cuck G, Fernandes RC, et al. (2006) Carcinoma of the renal pelvis and ureter. Int Braz J Urol 32: 648-653.

16. Holmäng S, Lele SM, Johansson SL (2007) Squamous cell carcinoma of the renal pelvis and ureter: incidence, symptoms, treatment and outcome. $J$ Urol 178: 51-56.

This article was originally published in a special issue, Gastrointestinal Cancer handled by Editor(s). Dr. Yu-Fei Jiao, Hospital of Harbin Medical University, China
17. Donnelly JD, Koontz WW (1975) Carcinoma of the renal pelvis: a ten-year review. South Med J 68: 943-946.

18. Kinn AC (1980) Squamous cell carcinoma of the renal pelvis. Scandinavian journal of urology and nephrology 14: 77-80.

19. Grace DA, Taylor WN, Taylor JN, Winter CC (1967) Carcinoma of the renal pelvis: a 15-year review. J Urol 98: 566-569.

20. Rizack T, Mega A, Berz D (2009) Is squamous cell histology an adverse prognosticator for survival of malignancies of the upper urinary tract? $\mathrm{J}$ Clin Oncol 27: 15s.

21. Bamias A, Deliveliotis Ch, Fountzilas G, Gika D, Anagnostopoulos A, et al. (2004) Adjuvant chemotherapy with paclitaxel and carboplatin in patients with advanced carcinoma of the upper urinary tract: a study by the Hellenic Cooperative Oncology Group. J Clin Oncol 22: 2150-2154.

22. Cozad SC, Smalley SR, Austenfeld M, Noble M, Jennings S, et al. (1992) Adjuvant radiotherapy in high stage transitional cell carcinoma of the renal pelvis and ureter. Int J Radiat Oncol Biol Phys 24: 743-745

23. Dasanu CA, Ong-Bacay A, Codreanu I (2011) Newer developments in the therapeutics of the transitional cell carcinoma of renal pelvis. $J$ Oncol Pharm Pract [Epub ahead of print].

24. Kwak C, Lee SE, Jeong IG, Ku JH (2006) Adjuvant systemic chemotherapy in the treatment of patients with invasive transitional cell carcinoma of the upper urinary tract. Urology 68: 53-57

25. Lerner SE, Blute ML, Richardson RL, Zincke H (1996) Platinum-based chemotherapy for advanced transitional cell carcinoma of the upper urinary tract. Mayo Clin Proc 71: 945-950

26. Michael M, Tannock IF, Czaykowski PM, Moore MJ (1998) Adjuvan chemotherapy for high-risk urothelial transitional cell carcinoma: the Princess Margaret Hospital experience. Br J Urol 82: 366-372.

27. Soga N, Arima K, Sugimura Y (2008) Adjuvant methotrexate, vinblastine adriamycin, and cisplatin chemotherapy has potential to prevent recurrence of bladder tumors after surgical removal of upper urinary tract transitional cell carcinoma. Int J Urol 15: 800-803

28. Cozad SC, Smalley SR, Austenfeld M, Noble M, Jennings S, et al. (1995) Transitional cell carcinoma of the renal pelvis or ureter: patterns of failure. Urology 46: 796-800

29. Murphy DM, Zincke H, Furlow WL (1980) Primary grade 1 transitional cell carcinoma of the renal pelvis and ureter. J Urol 123: 629-631.

30. Grabstald H, Whitmore WF, Melamed MR (1971) Renal pelvic tumors. JAMA 218: 845-854.

31. Guinan P, Vogelzang NJ, Randazzo R, Sener S, Chmiel J, et al (1992) Rena pelvic cancer: a review of 611 patients treated in Illinois 1975-1985. Cancer Incidence and End Results Committee. Urology 40: 393-399.

32. Rubenstein MA, Walz BJ, Bucy JG (1978) Transitional cell carcinoma of the kidney 25-year experience. J Urol 119: 594-597.

33. Edge SB, Compton CC (2010) The American Joint Committee on Cancer: the $7^{\text {th }}$ edition of the AJCC cancer staging manual and the future of TNM. Ann Surg Oncol 17: 1471-1474. 